\title{
Trial of three-day and ten-day courses of amoxycillin in otitis media
}

\author{
D M CHAPUT DE SAINTONGE, D F LEVINE, I TEMPLE SAVAGE, G W S BURGESS, J SHARP, \\ S R MAYHEW, M G SADLER, R MOODY, R GRIFFITHS, S GRIFFITHS, G MEADOWS
}

\begin{abstract}
A randomised double-blind controlled trial compared three-day and 10-day courses of amoxycillin $(25 \mathrm{mg} / \mathrm{kg}$ daily) in children with otitis media. Seventeen doctors from five centres admitted 84 children between the ages of 2 and 10 years. Symptoms and signs were measured on admission to the trial, on day 3 , and on day 15. Mothers' observations were recorded daily for 10 days. Audiograms were performed at four and 12 weeks after the end of the trial. The treatment groups showed little difference in the speed of resolution of symptoms and signs, the numbers of primary treatment failures, or the frequency of recurrent ear infections. There were no complications in either group.

Most children with otitis media can probably be successfully and safely treated with no more than a three-day course of amoxycillin providing their progress is reviewed about the fifth or sixth day after treatment started. This policy could save over $£ 1$ million annually in antibiotic costs.
\end{abstract}

\section{Introduction}

Most children have at least one attack of otitis media before they are 10 years old. ${ }^{1}$ This disease costs the USA hundreds of millions of dollars, ${ }^{2}$ of which a sizable proportion is spent on antibiotics. In England and Wales 1.5 million episodes occur annually, ${ }^{3}$ and most children will receive antibiotics. Although the present drug of choice in Britain may well be amoxycillin, ${ }^{4}$ the optimum length of treatment has never been established, but seven-day or 10-day courses are usual. The annual cost of prescribing amoxycillin for seven days for all children with otitis media is likely to be about $£ 3.9$ million.

For most infections the optimum duration of treatment is unknown. Uncomplicated urinary tract infections may be treated successfully with a three-day course ${ }^{5}$ or even a single dose, ${ }^{6}$ though much longer courses are common. In children com-

\footnotetext{
Clinical Trials Unit, Department of Clinical Pharmacology and

Therapeutics, London Hospital Medical College, London E1 2AD D M CHAPUT DE SAINTONGE, PHD, MRCP, clinical pharmacologist D F LEVINE, MRCP, lecturer

I TEMPLE SAVAGE, BPHARM, MSc, clinical research assistant

The Surgery, Hinnings Road, Distington, Cumbria

G W S BURGESS, MB, BCHIR, general practitioner

J SHARP, MB, general practitioner

Eaton Socon Health Centre, Huntingdon

S R MAYHEW, MB, DCH, general practitioner

Jenner Health Centre, Whittlesey, Peterborough PE7 1EJ

M G SADLER, MRCP, general practitioner

Heavitree Health Centre, Exeter EX1 2RX

R MOODY, BSC, MRCGP, general practitioner

35 High Street South, East Ham, London E6 4EN

R GRIFFITHS, MB, FRCGP, general practitioner

S GRIFFITHS, MB, FRCGP, general practitioner

G MEADOWS, MB, BS, general practitioner
}

pliance with antibiotic treatment for otitis media is poor, up to half failing to complete the full course. ${ }^{78}$ These facts, and the prospect of a possible saving of $£ 2 \cdot 2$ million annually, encouraged us to compare the efficacy of a three-day course of amoxycillin with that of a 10-day course.

\section{Patients and methods}

Seventeen general practitioners from five centres collaborated in the study. They were largely self-selected on the basis of interest in general otology or clinical trials. Several had had experience in ENT departments.

Entry criteria and exclusions-Otitis media was defined as "that acute painful condition of the middle ear which the practitioner usually calls otitis media and for which antibiotics are given." Participants were told that the sign of redness with bulging correlated best with the presence of bacterial infection. ${ }^{9}$ No effort was made to impose arbitrary diagnostic criteria or to attempt to ensure homogeneity of diagnostic criteria between doctors. Patients aged 2-10 years were entered after their parents had given informed consent and the following criteria had been satisfied: no history of chronic ear disease, not more than one attack of otitis media in the preceding year and none in the previous month; no symptoms for more than a week or complications already present; no acute exanthemata; no concurrent serious medical problems; and no previous penicillin allergy. General practitioners completed a checklist of these criteria for each patient. Most of the patients were admitted during the winters of 1979 and 1980 .

Measurements-Patients were assessed by the doctor at entry, on the third day of treatment, and between days 13 and 16 of treatment. The presence or absence of pain, hearing loss, blocked nose, cough, or fever was noted and the appearance of the eardrum recorded. Treatment failures were defined as patients whose rate of recovery was considered unsatisfactory by the general practitioner and who were consequently prescribed additional antibiotics on an open basis. Mothers were given a diary card on which to record earache (a lot/ some/none), wakefulness at night (a lot/some/none), loss of appetite, frequency of defecation, number of doses of analgesic required, and the amount of trial drug swallowed (all/some/none). Compliance was also assessed by the amount of medicine in the bottle when returned to the surgery. Audiograms were measured four weeks after the end of the trial and, if abnormal, again eight weeks later. Testing conditions were not standardised between centres but were performed by trained audiologists attached to the audiology service near the patient's home. Children who were too young for standard puretone audiograms were tested appropriately for their age. The presence of clinically significant hearing loss was judged in the first instance by the audiologist or the general practitioner and later by two independent ENT surgeons, who judged a mean hearing loss of more than $20 \mathrm{~dB}$ at 500,1000, and $2000 \mathrm{~Hz}$ to be clinically important. Patients were followed for 6-18 months after entry to the trial and further episodes of ear infection recorded.

Treatment regimens-The trial was conducted under double-blind conditions. All patients first received a bottle of amoxycillin syrup for three days. Children under five years were given $125 \mathrm{mg}$ in three doses daily; those over five years had double this dose. They were then randomly allocated to receive amoxycillin for a further seven days (the 10-day group) or a matching placebo (the three-day group). They were free to use analgesics or vasoconstrictors providing their identity and dose were recorded. In the event only four children were given vasoconstrictors, so their use was ignored in the analysis.

Statistical analysis-The effects of treatment were sought by analysis of variance and covariance after data transformation when necessary. Appropriate non-parametric tests were used for nominal data. Recurrence rates were compared using survival analysis, and predictors of success and failure by discriminant analysis. The data 
collected by the doctors were analysed twice. In the first analysis data from the dropouts and withdrawals were included up to and including their last assessment; in the second, conservative, analysis the treatment failures contributed their values at dropout to all subsequent assessments, even though they had left the trial. Thus a patient who was withdrawn from the trial on day 4 with an ear that was still red and painful contributed a red painful ear to the analysis at day 15 .

\section{Results}

Sample population-A total of 84 patients contributing 109 affected ears were entered into the trial. A further 75 patients were considered but failed to satisfy one or more of the admission criteria. Possibly many more cases were not admitted, for reasons which cannot now be discovered. Clinical features of patients on entry are shown in table I.

TABLE I-Clinical characteristics of sample population at entry to study

\begin{tabular}{|c|c|c|c|c|c|}
\hline \multicolumn{5}{|c|}{ Ear symptoms signs } & \multirow{2}{*}{$\begin{array}{c}\text { No of } \\
\text { patients }\end{array}$} \\
\hline Red drum & Bulging & Pain & Deafness & Dullness & \\
\hline $\begin{array}{l}+ \\
+ \\
+ \\
+ \\
+ \\
+ \\
+ \\
+ \\
+ \\
+ \\
+\end{array}$ & $\begin{array}{l}+ \\
+ \\
+ \\
+ \\
+\end{array}$ & $\begin{array}{l}+ \\
+ \\
+ \\
+ \\
+ \\
+ \\
+ \\
+\end{array}$ & $\begin{array}{l}+ \\
+ \\
+\end{array}$ & $\begin{array}{l}+ \\
+\end{array}$ & $\begin{array}{r}12 \\
2 \\
27 \\
1 \\
3 \\
9 \\
18 \\
1 \\
1 \\
3 \\
3 \\
2\end{array}$ \\
\hline
\end{tabular}

+ Present

TABLE II-Doctors' assessment of signs of illness. (Cough and blocked nose expressed as percentage of patients in whom sign was present; ear signs expressed as percentage of assessable ears; $95 \%$ confidence limits for the difference ( + ) given in parentheses)

\begin{tabular}{lcccc}
\hline $\begin{array}{c}\text { Symptom/ } \\
\text { sign }\end{array}$ & $\begin{array}{c}\text { Treatment } \\
\text { group }\end{array}$ & $\begin{array}{c}\text { On } \\
\text { admission }\end{array}$ & Day 3 & Day 15 \\
\hline Blocked nose & 3-day & 71 & 50 & 27 \\
& 10-day & 78 & 50 & 13 \\
Cough & 3-day & $( \pm 19)$ & $( \pm 28)$ & $( \pm 18)$ \\
& 10-day & 74 & 49 & 24 \\
Ear signs: & & $( \pm 19)$ & $( \pm 23)$ & $( \pm 19)$ \\
Hearing loss & 3-day & 23 & 7 & 7 \\
& 10-day & 16 & 17 & 5 \\
Pain & 3-day & $( \pm 14)$ & $( \pm 14)$ & $( \pm 8)$ \\
& 10-day & 54 & 8 & 1 \\
Discharge & 3-day & $( \pm 15)$ & $( \pm 8)$ & $( \pm 3)$ \\
& 10-day & 3 & 0 & 0 \\
Red drum & 3-day & $( \pm 4)$ & $( \pm 0)$ & $( \pm 0)$ \\
& 10-day & 64 & 35 & 7 \\
Dullness (loss & & $( \pm 15)$ & $( \pm 16)$ & $( \pm 11)$ \\
of light reflex) & 3-day & 46 & 26 & 3 \\
& 10-day & 58 & 33 & 18 \\
Bulging drum & 3-day & $( \pm 16)$ & $( \pm 15)$ & $( \pm 10)$ \\
& 10-day & 27 & 6 & 0 \\
& & $( \pm 14)$ & $( \pm 7)$ & $( \pm 0)$ \\
\hline
\end{tabular}

There were no significant differences between the two treatment groups in age, sex, number living in council or rented accommodation, or family contact with upper respiratory tract infections. There were significant differences between the five centres in the frequency of deafness and dullness and bulging of the eardrum on entry. This could only partly be attributed to differences in the age range of children attending.

Compliance-According to the amount of medicine returned, over $80 \%$ of the patients took $90 \%$ of the treatment or more. Mothers' records of the amounts swallowed by the children suggested that virtually all the medicine given was swallowed. Neither method of recording showed significant differences in compliance between the treatment groups or the centres.
Doctor's assessment-There was no significant difference between the groups in the speed of resolution of most of the symptoms or signs measured by the doctor (table II). The exception was dullness of the eardrum (loss of light reflex), which was commoner in the 10-day group at day 15. It was also commoner in this group at entry, though not significantly so. No patient in either group developed a new perforation or discharge during the trial. There was no treatment difference in these variables when patients under and over 5 years and the five centres were examined separately. When the treatment failures were allowed to contribute to the analysis after withdrawal, ear pain was more common in the three-day treatment group at the final assessment. No other differences appeared. The subset of 45 patients who presented with red bulging drums was examined separately but no difference in outcome could be detected whatever assessment was used.

Mothers' assessment-The rate of resolution of the symptom of earache in the two treatment groups is shown in fig 1 . There were no significant differences between the treatment groups or between the centres for any symptom except the frequency of defecation, which was significantly higher in the three-day treatment group on day three only.

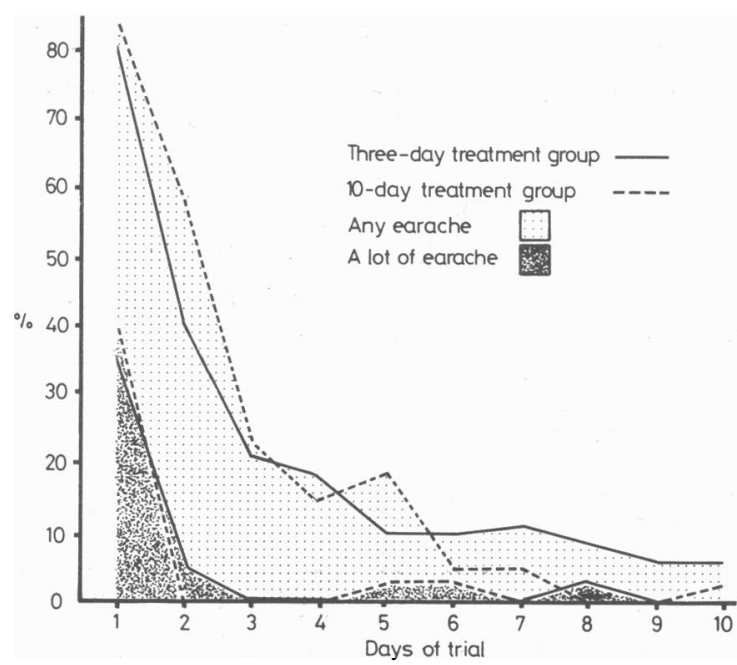

FIG 1-Proportion of children with earache recorded in mothers' diaries.

Audiology-At the first test significant differences appeared between the five centres in the mean hearing loss over the range $500-2000 \mathrm{~Hz}$. The mean hearing loss over this range did not differ significantly between the two treatments in either age group, nor did that over the range $250-8000 \mathrm{~Hz}$ (fig 2). Eleven of the 35 patients in the 10-day treatment group and six of the 35 in the three-day treatment group were judged by the audiologist or general practitioner to have significant hearing loss at the time of the first assessment and were seen again two months later. The independent assessors considered that 20 patients in each group had significant loss at the first visit. Fifteen children attended for a follow-up audiogram three months after the end of the trial. Three out of five in the three-day and six out of 10 in the 10-day treatment group were judged by the independent assessors to have appreciable hearing loss. At the time of the test, two children in each group had colds, blocked noses, recent recurrence of otitis media, or other reasons for impaired hearing.

Recurrences-The median length of follow-up was 12 months and was similar for both treatment groups. Of the patients entered into the trial, eight of 42 and seven of 42 in the three-day and 10-day groups respectively had further attacks of otitis media. Five of the 33 patients taking the three-day course and who completed the active treatment had recurrences as did seven of the 38 in the 10-day group. Most recurrences occurred within 12 weeks of entry to the trial, but the rates were not significantly different between the treatment groups, the five centres, or the age groups. No child developed any complication of otitis media. Children under 5 years tended to have higher recurrence rates, but this did not reach conventional levels of significance.

Withdrawals-Thirteen patients failed to complete the full course of treatment, the reasons are shown in table III; eight (five in the three-day and three in the 10-day group) needed further antibiotic treatment because of poor response and must be considered as treat- 
ment failures. Five patients were withdrawn because of possible adverse effects, mainly diarrhoea. This developed in four patients two or three days after the antibiotic was stopped while they were taking placebo. In three cases other members of the family had diarrhoea, so the effect may well have been unrelated to treatment. Treatment failures were significantly more common among children who entered the trial without cough or blocked nose, but no other variable or combination of variables could be used to predict failure satisfactorily.

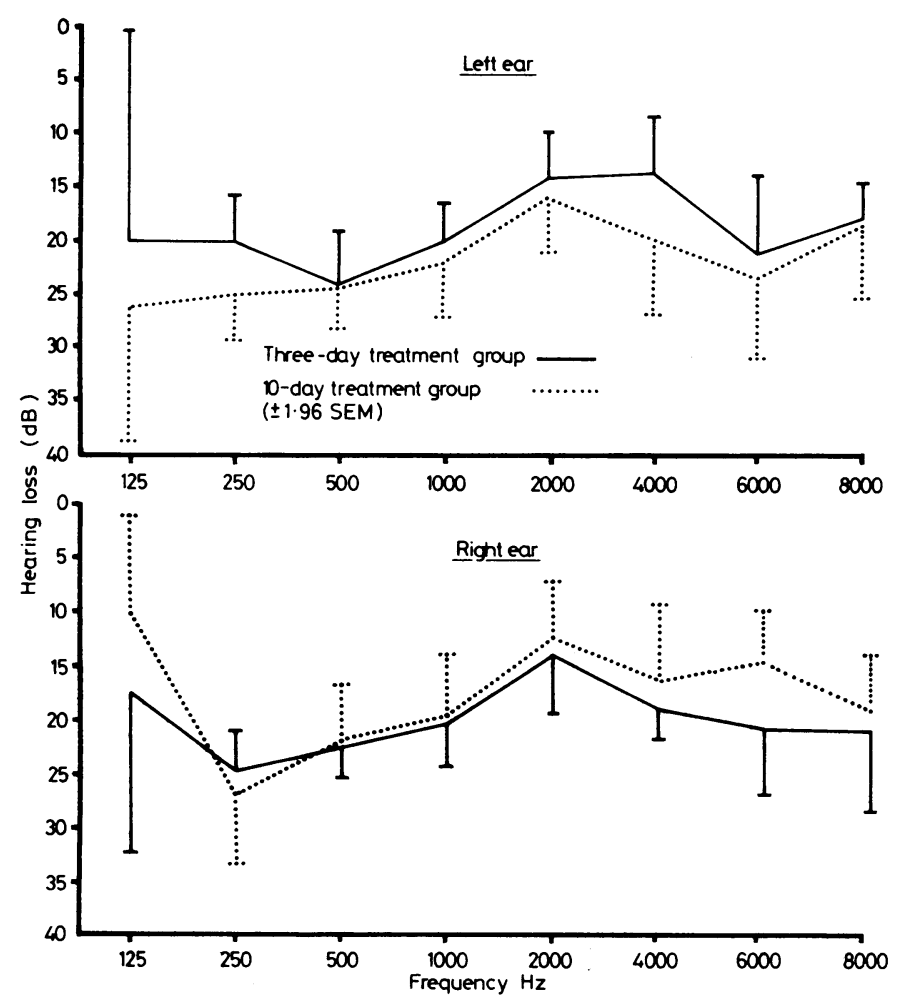

FIG 2-Hearing loss at first audiogram in both ears.

TABLE III-Patients withdrawn from the trial

\begin{tabular}{|c|c|c|c|c|}
\hline Case No & $\begin{array}{l}\text { Treatment } \\
\text { group }\end{array}$ & $\begin{array}{l}\text { Time of } \\
\text { withdrawal }\end{array}$ & Reason/action taken & $\begin{array}{l}\text { Treatment } \\
\text { failure? }\end{array}$ \\
\hline 1 & 3-day & Day 9 & $\begin{array}{l}\text { Ear better then worse, } \\
\text { amoxycillin prescribed }\end{array}$ & Yes \\
\hline 2 & 3-day & Day 8 & $\begin{array}{l}\text { Improved day } 2-3 \text { then worse } \\
\text { again, co-trimoxazole } \\
\text { prescribed }\end{array}$ & Yes \\
\hline 3 & 3-day & Day 4 & $\begin{array}{l}\text { “No better,” co-trimoxazole } \\
\text { prescribed }\end{array}$ & Yes \\
\hline 4 & 3-day & Day 7 & $\begin{array}{l}\text { "Not much improvement," } \\
\text { cephalexin prescribed }\end{array}$ & Yes \\
\hline 5 & 3-day & Day 10 & $\begin{array}{l}\text { Ear pain day } 8 \text { to end (? non- } \\
\text { compliant), amoxycillin } \\
\text { prescribed }\end{array}$ & Yes \\
\hline 6 & 10-day & Day 10 & $\begin{array}{l}\text { "Drum still red," extra anti- } \\
\text { biotics prescribed }\end{array}$ & Yes \\
\hline $7^{*}$ & 10-day & Day 10 & $\begin{array}{l}\text { "No improvement in ears after } \\
\text { full treatment with trial } \\
\text { preparation," cephalexin } \\
\text { prescribed }\end{array}$ & Yes \\
\hline $8^{*}$ & 10-day & Day 4 & $\begin{array}{l}\text { “Not much improvement," also } \\
\text { non-compliant with dose } \\
\text { schedule amoxycillin } \\
\text { prescribed }\end{array}$ & Yes \\
\hline 9 & 10-day & Day 6 & $\begin{array}{l}\text { Diarrhoea and sickness also non- } \\
\text { compliant, no further } \\
\text { treatment }\end{array}$ & No \\
\hline 10 & 3-day & Day 6 & $\begin{array}{l}\text { Diarrhoea started day } 6, \text { no } \\
\text { further treatment }\end{array}$ & No \\
\hline 11 & 3-day & Day 6 & $\begin{array}{l}\text { Diarrhoea started day } 5 \text {, no } \\
\text { further treatment }\end{array}$ & No \\
\hline 12 & 3-day & Day 6 & $\begin{array}{l}\text { Diarrhoea and rash started day } \\
5 \text {, no further treatment }\end{array}$ & No \\
\hline 13 & 3-day & Day 6 & $\begin{array}{l}\text { Diarrhoea started day } 6 \text {, no } \\
\text { further treatment }\end{array}$ & No \\
\hline
\end{tabular}
* In cases 7 and 8 the patients were brothers; their sister, who was also in the trial,
had diarrhoea but was not withdrawn.

\section{Discussion}

We have been unable to show any convincing difference between three-day and 10-day courses of amoxycillin, either in the speed of resolution of symptoms and signs or in the frequency of recurrences and complications. Whether the trial was sufficiently powerful to exclude effectively a clinically important difference is a matter of opinion, because it depends on how such a difference is defined. There were five primary treatment failures in the three-day and three in the 10-day treatment groups. In two of the three-day group an initial improvement was followed by deterioration when they started placebo. Although these two might not have failed with a 10-day course, our pattern of surveillance was slightly biased in favour of finding relapses in the three-day group. A conservative analysis, which retained treatment failures, showed deafness to be more common in the three-day group at 15 days but no other treatment differences. Because a very large number of statistical tests were performed a number of "significant differences" would be expected to occur through chance alone, and our findings must be interpreted in this light. Examination of the $95 \%$ confidence limits for the recurrence rates suggests that the true difference between three-day and 10-day courses lies between 13\% more recurrences on three days' treatment and $7 \%$ more recurrences on 10 days'.

The trial indicated several differences between the centres taking part. The differences in mean hearing loss may have been due simply to differences in calibration of the instruments or ambient noise levels. Since we made no effort to standardise the audiology testing in the five centres some differences between them were not unexpected. Although variance attributable to this source will have reduced the power of the trial, it is unlikely to have biased the results since audiologists were unaware of the treatment allocation, which was balanced within centres. Differences in patient characteristics, however, may reflect different admitting policies and call into question the nature of the "otitis media" represented in our trial sample. Although our patients would have satisfied the diagnostic criteria of other recent studies, ${ }^{10}{ }^{11}$ readers must judge for themselves (from table I) whether their own are satisfied. It could be argued that only patients with confirmed bacterial infections should have been admitted to this trial of antibiotics, since only in these patients is treatment likely to be effective. Inclusion of other patients would tend to obscure treatment effects in a small responsive subgroup. Unfortunately, bacterial infection of the middle ear can be established only by tympanocentesis, which is unacceptable as a routine measure to general practitioners in Britain. Although many of our patients possibly did not have bacterial otitis media, we could not identify any subgroup on the basis of combinations of symptoms and signs who did any worse with either treatment.

If the economic objective of this trial is to be achieved the evidence must be sufficient to alter the prescribing behaviour of general practitioners on a large scale. Before this can happen they must be convinced not only that we studied an appropriate group of patients but that we effectively excluded the chance of serious complications of otitis media being more common in the three-day treatment group. The frequency of such complications as mastoiditis and meningitis in a conventionally treated group without previous ear disease is unknown, but it seems unlikely to be greater than 1 in 1000 . For a study to be $90 \%$ sure of detecting a doubling in the frequency, significant at the 0.05 level, at least 50000 patients would need to be studied. Such a trial is unlikely ever to be mounted, so that specific reassurance will probably never be given on this point. Indeed, although the decline in incidence of complications has been attributed to the coincident rise in the use of antibiotics in general, there is no proof that this association is causal. The view that all children with otitis media need antibiotics has been challenged. ${ }^{12}{ }^{13}$ It has even been suggested that the use of antibiotics is an important predisposing factor in the development of recurrent infections. ${ }^{14}$ Antibiotics may also do harm through their unwanted effects. 
The results of our present trial suggest that there may be little important difference between three-day and 10-day courses of amoxycillin. Within the sample of patients we studied a number undoubtedly had a self-limiting disease which required no antibiotic treatment at all. There may also have been a group for whom three-day or even 10-day treatment would have been inadequate. We cannot, in retrospect, identify any of these groups. Nevertheless, most of the improvement in symptoms clearly occurs in the first few days. We suggest that patients with otitis media who need antibiotics should be treated for three days only and then reassessed at about the fifth or sixth day after starting treatment. Only those whose rate of improvement is unsatisfactory should have antibiotics for longer. The relatively high frequency of hearing loss in both groups three months after an episode is not unexpected and emphasises the need to follow up these patients until hearing returns to normal. We have shown that this form of management is practicable in British general practice and could save the Health Service over $£ 1$ million annually in antibiotic costs without reducing the standard of care. Whether overall savings would result from this policy can be determined only by a full cost-benefit analysis, which we have not attempted.

We thank Mr J B Booth and Mr S J Abramovich, who acted as independent assessors of the audiograms. We gratefully acknowledge the generous financial support from the special trustees of the London Hospital, without whom this trial could not have taken place. We also thank Messrs Edwin Burgess for sensible graduated 2-5 ml plastic spoons and Messrs Bencard for trial supplies.

\section{References}

${ }^{1}$ Howie VM. Acute and recurrent otitis media. In: Jaffe B, ed. Hearing los in children. Baltimore: University Park Press, 1977.

2 Anonymous. Otitis media. FAMA 1980;244:2603.

${ }^{3}$ Royal College of General Practitioners, Office of Population Censuses and Surveys, Department of Health and Social Security. Morbidity statistics from general practice 1971-2. London: HMSO, 1979.

- Anonymous. Antibiotics for otitis media. Br Med f 1976;ii:1407.

5 Charlton CAC, Crowther A, Davies JG, et al. Three-day and 10-day chemotherapy for urinary tract infections in general practice. $\mathrm{Br} \mathrm{Med} \mathcal{F}$ 1976 ; : $124-6$.

- Fang LST, Tolkoff-Rubin HE, Rubin RH. Efficacy of single dose and conventional amoxycillin therapy in urinary tract infection localised by the antibody-coated bacteria technic. $N$ Engl f Med 1978;298:413-6.

${ }^{7}$ Becker MH, Drachman RH, Kirscht JP. Motivations as predictors of health behaviour. Health Services Rep 1972;87:852-61.

8 Charney E, Bynum R, Eldredge D, et al. How well do patients take oral penicillin ? A collaborative study in private practice. Paediatrics 1967 40:188-95.

- Halstead C, Lepow ML, Balassanian H, Emmerich J, Wolinsky E. Otitis media. Clinical observations, microbiology, and evaluation of therapy. Am $\mathcal{F}$ Dis Child 1968;115:542-51.

10 Van Buchem FL, Dunk JHM, Van't Hof MA. Therapy of acute otitis media: myringotomy, antibiotics or neither? Lancet 1981 ;ii:883-7.

11 Froom J, Mold J, Culpepper L, Boisseau V. The spectrum of otitis media in family practice. $\mathcal{F}$ Fam Pract 1980;10:599-605.

${ }^{12}$ Fry J. Profiles of common diseases. 1966, London \& Edinburgh: E \& S Livingstone 1966.

13 Thomson J, Meistrup-Larsen KI, Sorenson H, Larsen PK, Mygind N. Penicillin and acute otitis: short and long-term results. Ann Otol Rhino Laryngol 1980;89 suppl $68: 271-4$.

14 Diamant $M$, Diamant B. Abuse and timing of use of antibiotics in acute otitis media. Arch Otolaryngol 1974;100:226-32.

(Accepted 24 February 1982)

\title{
Survival and desferrioxamine in thalassaemia major
}

\author{
B MODELL，E A LETSKY，D M FLYNN，R PETO，D J WEATHERALL
}

\begin{abstract}
A small randomised trial and observation of all patients homozygous for beta-thalassaemia in Britain born in or before 1963 indicated that those patients who had received average weekly doses of more than $4 \mathrm{~g}$ of desferrioxamine over the previous few years were less likely to die in the near future than were patients of similar ages who had received less, or no, desferrioxamine.
\end{abstract} Department of Obstetrics and Gynaecology, University College
Hospital, London WC1

B MODELL, MB, PHD, honorary consultant in perinatal medicine

Hospital for Sick Children, Great Ormond Street, London WC1N 3JH E A LETSKY, MB, MRCPATH, honorary consultant

Royal Free Hospital, London NW3 2QG

D M FLYNN, MD, MRCP, consultant paediatrician

Clinical Trial Service Unit, Nuffield Department of Clinical Medicine, Radcliffe Infirmary, Oxford OX2 6HE

R PETO, MA, MSC, reader in cancer studies

MRC Molecular Haematology Unit, Nuffield Department of Clinical Medicine, University of Oxford, John Radcliffe Hospital, Oxford OX3 9DU

D J WEATHERALL, FRCP, FRCPATH, FRS, Nuffield professor of clinical medicine and honorary director, MRC Molecular Haematology Unit

\section{Introduction}

Patients homozygous for $\beta$-thalassaemia die of anaemia in infancy unless regularly transfused. Each unit of blood contains about $200 \mathrm{mg}$ of iron, however, so that patients treated only by regular transfusion usually die in their second or third decade from the chronic effects of iron deposited in the myocardium. Early attempts to control iron overload by daily intramuscular injection of the iron-chelating agent desferrioxamine showed that iron excretion would balance iron input only when the concentration of iron in the body was undesirably high. ${ }^{1-4}$ When the drug is administered by slow subcutaneous infusion, however, a given dose is more effective and larger doses may be used; hence this approach may more successfully control iron overload. ${ }^{5-9}$ Regular parenteral infusion of desferrioxamine is cumbersome and expensive, and it is therefore desirable to know whether iron-chelation treatment measurably alters the survival of patients with transfusion-dependent $\beta$-thalassaemia.

In Britain children with $\beta$-thalassaemia major were first given desferrioxamine in 1962, and since 1967 some have received daily intramuscular injections amounting to an average of about $4 \mathrm{~g}$ a week, in the hope of postponing or even preventing cardiac death. ${ }^{34}$ The numbers of children treated with desferrioxamine have increased steadily, though many at first received the drug only intravenously at the time of transfusion or in infrequent short intramuscular courses that would not be expected to achieve a net iron balance in a transfusion-dependent child. In the late $1970 \mathrm{~s}$, as a result of the gradual accumulation of evidence for its value, practically all patients in Britain had begun regular subcutaneous infusions of desferrioxamine.

We present details of drug doses and survival for all patients 